\title{
BMJ Open Farm environment during infancy and lung function at the age of 31 : a prospective birth cohort study in Finland
}

Jussi Lampi, ${ }^{1,2}$ Heikki Koskela, ${ }^{3}$ Anna-Liisa Hartikainen, ${ }^{4}$ Adaikalavan Ramasamy, ${ }^{5,6,7}$ Alexessander Couto Alves, ${ }^{6}$ Marjo-Riitta Järvelin,, 6,8,10,11 Juha Pekkanen ${ }^{1,2}$

To cite: Lampi J, Koskela $\mathrm{H}$, Hartikainen A-L, et al. Farm environment during infancy and lung function at the age of 31: a prospective birth cohort study in Finland. BMJ Open 2015;5:e007350. doi:10.1136/bmjopen-2014007350

- Prepublication history for this paper is available online. To view these files please visit the journal online (http://dx.doi.org/10.1136/ bmjopen-2014-007350).

Received 2 December 2014 Revised 22 May 2015 Accepted 30 June 2015
CrossMark

For numbered affiliations see end of article.

Correspondence to

Jussi Lampi;

jussi.lampi@thl.fi

\section{ABSTRACT}

Objectives: Farming as an occupation is considered a risk factor for asthma and reduced lung function. By contrast, living on a farm during infancy has been reported to be associated with lower risk of asthma in adulthood. However, little is known about the association between farming environment during infancy and lung function in adulthood. We aimed to study the prospective longitudinal association between farming environment during infancy and lung function in adulthood.

Design: A prospective birth cohort study.

Setting: Northern Finland.

Participants: 5666 participants born in 1966 were followed up at the age of 31 years.

Primary outcome measures: Spirometry at the age of 31 years.

Results: To be born into a farmer's family was associated with higher forced expiratory volume in $1 \mathrm{~s}$ (FEV1) (36 mL; $95 \% \mathrm{Cl} 6$ to $67 \mathrm{~mL}$ ) and forced vital capacity (FVC) (40 mL; $95 \% \mathrm{Cl} 5$ to $75 \mathrm{~mL}$ ) at the age of 31 years. Contact with farm animals during infancy was associated with higher FEV1. No associations were seen with FEV1/FVC (FEV1/FVC ratio). Having dogs in childhood revealed similar associations. There was a suggestive dose-dependent association with the number of animal species during childhood and higher FEV1 and FVC at adulthood, especially among women. Conclusions: Farming environment in early life may have a positive impact on lung function in adulthood.

\section{INTRODUCTION}

Farming environment during infancy, especially contact with farm animals, is associated with decreased risk of asthma and allergic diseases. $^{1-3}$ Microbial exposure on a farm during infancy may inhibit the development of the allergic phenotype by influencing the development of the immune system. ${ }^{1}$ On the other hand, respiratory diseases such as asthma, allergic rhinitis, organic dust syndrome and extrinsic allergic alveolitis are

\section{Strengths and limitations of this study}

- The prospective nature of the study allowed analysis of longitudinal associations between farming environment during infancy and lung function at the age of 31 years without possible recall bias.

- The information was comprehensive about the factors in infancy that may affect lung function, including birth weight and pregnancy information.

- Although work and home-based exposure to cold, dust, solvents and tobacco, as well as occupation at the age of 31 years, were taken into account, detailed post-childhood information about farming exposures was lacking.

- Owing to lack of information about physical activity during childhood, its effect on lung function at the age of 31 years cannot be estimated.

well-known occupational health problems among farmers. ${ }^{4}$ In a farming environment, especially with farm animals, constant exposure to dust (organic and inorganic), chemicals (eg, pesticides and fertilisers), gases, fumes and infectious agents, ${ }^{4}$ may irritate and induce inflammation in the respiratory system ${ }^{5}{ }^{6}$ lead to impairment of lung function $^{7-12}$ and be a risk factor for respiratory diseases, for example, asthma. ${ }^{4-6}$ Therefore, living in a farm environment during infancy may reduce the risk of asthma and allergic diseases in adulthood, whereas exposure during adulthood may be a risk factor for respiratory diseases. There is a lack of longitudinal studies on the effect of farming environment during infancy and lung function in adulthood. The present prospective birth cohort study, with detailed questionnaire data regarding infancy and childhood environment, offered an excellent opportunity to 
investigate the effect of farming environment in infancy, especially contact with farm animals, on lung function measured by spirometry, at the age of 31 years.

\section{METHODS}

The Northern Finland Birth Cohort 1966 (NFBC1966) is a prospective study of 12058 live births from Oulu and Lapland, the two northernmost provinces of Finland, and covered $96 \%$ of the children born in that region between 1 January and 31 December 1966. In 1997, 8463 survivors still living in northern Finland or in the capital city area received a postal questionnaire and invitation to clinical examinations. A detailed description of the number of participants and flow charts of the 31-year follow-up study are shown on the study website. ${ }^{13}$ The current analyses included those 5666 participants who had complete spirometry data at the age of 31 years and who were not pregnant. The participants gave written informed consent.

\section{Antenatal and childhood factors}

Information about the farming environment, lifestyle factors, maternal factors and sociodemographic factors in infancy were collected from the mother during her pregnancy and/or immediately after delivery. ${ }^{2}$ Parental professional farming was defined if the participant's mother, father or both were classified as professional farmers. Childhood information about having farm animals (species and counts), place of residence, residential density, maternal education, maternal age, maternal BMI, smoking during pregnancy from the second month, mother's age of menarche and parity number, gestational age at birth, birth weight and height were collected during pregnancy and/or immediately after delivery. Residential density was defined as number of participants in the household divided by number of rooms in the household. Data obtained from hospital discharge registry were used to identify patients with pneumonia before the age of 7 years. Information about smoking at the age of 14 years was collected, with questionnaires sent to participants and parents in 1980.

\section{Assessment at the age of 31 years}

During follow-up at the age of 31 years, participants underwent a clinical examination, spirometry and skin prick tests, and filled in a health questionnaire. Lung function was assessed by forced vital capacity (FVC) and forced expiratory volume in $1 \mathrm{~s} \quad\left(\mathrm{FEV}_{1}\right)$ using a Vitalograph P-model spirometer (Vitalograph Ltd, Buckingham, UK) with a volumetric accuracy of $2 \%$ or $50 \mathrm{~mL}$, whichever was greater. The spirometer was calibrated regularly using a $1 \mathrm{~L}$ precision syringe. The spirometric manoeuvre was performed three times, but was repeated if the difference between two maximal readings for $\mathrm{FEV}_{1}$ or FVC was $>4 \%$. The highest $\mathrm{FEV}_{1}$ and FVC were used. Those in the skin prick test with a mean weal reaction $\geq 3 \mathrm{~mm}$ to one or more of the four allergens tested were considered to be atopic. Participants with a positive reaction to the negative control or negative reaction to histamine $(<3 \mathrm{~mm})$ were excluded. At 31-year follow-up, participants also filled in questionnaires that included queries on health and lifestyle factors, ownership of a cat or a dog before the age of 7 years (retrospectively) and sociodemographic factors. ${ }^{2}$ Doctor-diagnosed asthma ever at the age of 31 years was based on self-report. ${ }^{2}$

\section{Statistical analyses}

The final analyses included those 5666 participants who had complete spirometry data and were not pregnant. Multivariate linear models were used to analyse associations between farm environment, potential confounders and lung function. We identified, a priori, the list of potential confounders. At the age of 31 years, potential confounders were height, weight, physical activity, education, smoking, exposure to cold, dust, solvents and tobacco smoke at work/or at home, paternal asthma, maternal asthma, paternal allergy and maternal allergy. Potential childhood confounders were height, weight and gestational age at birth, residential density, pneumonia before the age of 7 years and smoking at the age of 14 years. Potential maternal confounders were mother's menarcheal age, parity number, age, education and smoking during pregnancy (after the second month of pregnancy). For the final models, we included all variables that were associated with outcome at $\mathrm{p}<0.1$ level and changed the estimate for the gender-adjusted association between farm animals during infancy and outcome $\left(\mathrm{FVC}, \mathrm{FEV}_{1}\right)$ by more than $10 \%$. Models for $\mathrm{FEV}_{1}$ were adjusted for gender, along with height, weight, smoking, education, exposure to solvents and tobacco smoke at home, and physical activity, at the age of 31 years; and smoking at the age of 14 years, birth height and weight, maternal education, paternal asthma and maternal age. Models for FVC were adjusted for gender, height, weight, smoking, education, exposure to solvents and tobacco smoke at home and physical activity at the age of 31 years; and birth height and weight, maternal education and residential density during infancy. Models for $\mathrm{FEV}_{1} / \mathrm{FVC}$ were adjusted with confounders selected for models for both $\mathrm{FEV}_{1}$ and FVC.

Among included participants, the maximum percentage of missing data was $4.4 \%$ for diseases, $0.9 \%$ for farm characteristics collected during the mother's pregnancy, $4.6 \%$ for pet ownership collected at the 31-year follow-up, and $2.9 \%$ for data on current occupation. For statistical analyses, missing data for confounders were classified as a separate category. The highest percentage of missing information concerned allergic conditions of the father $(12.8 \%)$. All analyses were conducted with IBM SPSS.

\section{RESULTS}

Characteristics and overall prevalence of allergic and respiratory diseases among study population at the age 
of 31 years are described in table 1 . Having a parent who was a professional farmer during one's infancy was significantly associated with increased $\mathrm{FEV}_{1}$ and FVC at the age of 31 years (table 2). Furthermore, having farm animals during one's infancy was associated with significantly increased $\mathrm{FEV}_{1}$ at the age of 31 years (table 2). Having dogs in childhood revealed similar associations (table 2). No associations were detected with $\mathrm{FEV}_{1} / \mathrm{FVC}$.

There was a suggestive association between the number of animal species during childhood and increasing lung function at the age of 31 years (table 2), especially among women (table 3). Further adjustment for current farming occupation at the age of 31 years had no impact on the size of the estimates of the observed significant associations on table 2 (data not shown). Although associations between farming environment and higher lung function at the age of 31 years were most evident among women, no significant gender interactions $(p<0.05)$ were observed. The smallest $p$ value was observed for the interaction between gender and having cats in childhood (FVC, $\mathrm{p}=0.09$ ), reaching almost nominal statistical significance. Other $p$ values for interaction between gender and having dogs during childhood, having farm animals, or family being involved in professional farming during infancy ranged between $\mathrm{p}=0.18$ and 0.92 .

To explore if the associations in table 2 are mediated via the protective effect of childhood farm life on atopy or asthma, ${ }^{2}$ the models were further adjusted for atopy

Table 1 Characteristics of the study population at the age of 31 years, stratified by parental professional farming during infancy

\begin{tabular}{|c|c|c|c|c|}
\hline & \multicolumn{4}{|c|}{$\begin{array}{l}\text { Parental professional farming } \\
\text { during infancy }\end{array}$} \\
\hline & \multicolumn{2}{|c|}{ No } & \multicolumn{2}{|c|}{ Yes } \\
\hline & $\mathrm{n}$ & Mean & $\mathrm{n}$ & Mean \\
\hline FVC (L) & 4367 & 4.75 & 1299 & 4.73 \\
\hline FVC (\% predicted) & 4367 & 96.5 & 1299 & $97.4^{*}$ \\
\hline $\mathrm{FEV}_{1}(\mathrm{~L})$ & 4367 & 3.97 & 1299 & 3.97 \\
\hline $\mathrm{FEV}_{1}$ (\% predicted) & 4367 & 96.7 & 1299 & $97.7^{\star}$ \\
\hline $\mathrm{FEV}_{1} / \mathrm{FVC}(\%)$ & 4367 & 84.0 & 1299 & 84.3 \\
\hline Height $(\mathrm{cm})$ & 4367 & 171.5 & 1299 & $170.7^{\star}$ \\
\hline \multirow[t]{2}{*}{ Weight (kg) } & 4367 & 72.8 & 1299 & 72.9 \\
\hline & $\mathbf{n}$ & Per cent & $\mathbf{n}$ & Per cent \\
\hline Female & 2178 & 49.9 & 672 & 51.7 \\
\hline Current smoking & 1350 & 30.9 & 327 & $25.2^{\star}$ \\
\hline High school graduate & 1785 & 40.9 & 369 & $28.4^{\star}$ \\
\hline Atopy & 1395 & 33.5 & 254 & $20.4^{*}$ \\
\hline DD asthma† & 364 & 8.5 & 94 & 7.3 \\
\hline \multicolumn{5}{|c|}{$\begin{array}{l}\text { Atopy: Participants with a weal reaction } \geq 3 \mathrm{~mm} \text { to one or more of } \\
\text { the four allergens tested were considered to be atopic. } \\
\text { * } p \text { Value }<0.05 \text {. } \\
\text { tDD asthma } n=5586 \text {; atopy } n=5416 \text {. } \\
\text { DD, doctor-diagnosed ever; } F E V_{1} \text {, forced expiratory volume in } 1 \mathrm{~s} \text {; } \\
\text { FVC, forced vital capacity. }\end{array}$} \\
\hline
\end{tabular}

and asthma (table 4). Atopy and doctor-diagnosed asthma reduced the size of the estimates in table 2 by $50 \%$ at the most. This suggests that although atopy and asthma probably mediate the effect on improved lung function, other pathways are also likely to be operational.

\section{DISCUSSION}

To the best of our knowledge, this is the first prospective birth cohort study on the association between a farming environment during infancy and lung function in adulthood. The results suggest that a farming environment during infancy is associated with higher $\mathrm{FEV}_{1}$ and FVC at the age of 31 years. No associations with $\mathrm{FEV}_{1} / \mathrm{FVC}$ were observed. Our findings suggest that farming environment in early life may have a positive impact on lung function in adulthood.

Respiratory diseases are well-known occupational health problem among farmers. ${ }^{4}$ Lowered lung function has been reported among farmers in occupational settings, ${ }^{78}$ and especially among those working with farm animals, in longitudinal studies. ${ }^{9}{ }^{10}$ Furthermore, Eduard et al reported reduced $\mathrm{FEV}_{1}$ among livestock farmers compared to crop farmers, however, with no association with FVC. ${ }^{11}$ Environmental exposure to animal houses has also been reported to be associated with decreased $\mathrm{FEV}_{1} \cdot{ }^{12}$ On the other hand, Omland et $a l^{14}$ reported that there were no associations between occupational farming and lung function, with similar findings being described between dairy farmers and controls, in a longitudinal study. ${ }^{15}$ The effect of an early farm life environment on lung function is less clear. Merchant $e t a l^{16}$ reported that children born on farms had higher FVC compared with children not born on a farm. However, most studies have reported that living on a farm in childhood has no effect on lung function on childhood ${ }^{17} 18$ or adulthood. ${ }^{19}$ There is lack of prospective longitudinal studies on the matter.

By contrast, numerous reports have been published over the past decade concerning the association between farming environment during infancy and decreased risk of allergic diseases and asthma. ${ }^{1-3}$ It has been hypothesised that high microbial exposure in a farming environment may affect development of the immune system during childhood and promote nonallergic phenotypes. ${ }^{1}$ Some studies have reported that high microbial exposure, such as exposure to bacterial endotoxin (the Gram-negative bacterial cell wall component), may affect the development of the immune system $^{2021}$ and lead to reduced risk of asthma in childhood. ${ }^{120} 22$ On the other hand, high exposure to endotoxin may also irritate the airways, and be a source of airway inflammation and obstruction not only in the occupational setting, ${ }^{6}$ but also during infancy when exposure to endotoxin may be a risk factor for wheezing. ${ }^{22}$ So, microbial exposure during infancy may promote development of non-allergic phenotype and decreased risk of allergic diseases and asthma, ${ }^{1}$ but it 
Table 2 Associations between farming environment during infancy and lung function at the age of 31 years

\begin{tabular}{|c|c|c|c|c|c|c|c|}
\hline \multirow[b]{2}{*}{ Farm-related factors during infancy } & \multirow[b]{2}{*}{$\mathbf{N}$} & \multicolumn{3}{|c|}{ FEV 1 difference $(\mathrm{mL})$} & \multicolumn{3}{|c|}{ FVC difference $(\mathrm{mL})$} \\
\hline & & Crude & Adj & $95 \% \mathrm{Cl}$ & Crude & Adj & $95 \% \mathrm{Cl}$ \\
\hline \multicolumn{8}{|l|}{ Parental professional farming } \\
\hline No & 4367 & 0 & 0 & & 0 & 0 & \\
\hline Yes & 1299 & 44 & 36 & (6 to 67 ) & 42 & 40 & (5 to 75$)$ \\
\hline \multicolumn{8}{|l|}{ Family had farm animals } \\
\hline No & 3930 & 0 & 0 & & 0 & 0 & \\
\hline Yes & 1692 & 39 & 32 & (3 to 61 ) & 14 & 11 & $(-22$ to 43$)$ \\
\hline \multicolumn{8}{|l|}{ Family had dogs* } \\
\hline No & 2478 & 0 & 0 & & 0 & 0 & \\
\hline Yes & 2995 & 34 & 36 & (10 to 61$)$ & 37 & 37 & (8 to 67$)$ \\
\hline \multicolumn{8}{|l|}{ Family had cats* } \\
\hline No & 2767 & 0 & 0 & & 0 & 0 & \\
\hline Yes & 2640 & 18 & 15 & $(-11$ to 41$)$ & 16 & 14 & $(-16$ to 44$)$ \\
\hline \multicolumn{8}{|l|}{ Number of animal speciest } \\
\hline 0 & 1476 & 0 & 0 & & 0 & 0 & \\
\hline 1 & 1539 & 39 & 39 & (6 to 73$)$ & 41 & 41 & (2 to 79$)$ \\
\hline 2 & 1046 & 53 & 56 & (18 to 94 ) & 32 & 30 & $(-14$ to 74$)$ \\
\hline 3 & 663 & 67 & 65 & (20 to 109$)$ & 54 & 51 & (0 to 103 ) \\
\hline 4 or more & 485 & 55 & 44 & $(-6$ to 94$)$ & 48 & 43 & $(-14$ to 100$)$ \\
\hline \multicolumn{8}{|l|}{ Number of cows } \\
\hline 0 & 3970 & 0 & 0 & & 0 & 0 & \\
\hline $1-4$ & 878 & 36 & 31 & $(-6$ to 67$)$ & 17 & 12 & $(-30$ to 53$)$ \\
\hline 5 or more & 767 & 46 & 35 & ( -3 to 73$)$ & 18 & 16 & $(-27$ to 59$)$ \\
\hline \multicolumn{8}{|c|}{$\begin{array}{l}\text { Crude: adjusted for gender and height at the age of } 31 \text { years. } \\
\text { Adj: multivariate model, for more detailed information see Methods section. } \\
{ }^{*} \text { Before the age of } 7 \text { years. } \\
\text { tlncludes cows, pigs, sheep, poultry, minks, cats and dogs. } \\
\text { FEV }{ }_{1} \text {, forced expiratory volume in } 1 \text { s; FVC, forced vital capacity. }\end{array}$} \\
\hline
\end{tabular}

may also be a risk factor for occupational asthma, and other occupational respiratory diseases such as organic dust syndrome and chronic bronchitis. ${ }^{4}$

In the present study, farming environment during infancy was associated with higher $\mathrm{FEV}_{1}$ and FVC but not with $\mathrm{FEV}_{1} / \mathrm{FVC}$. These spirometric findings suggest that a non-farming environment is associated with lower lung volumes, not airflow limitation. This is an unexpected finding, since farming environment is mainly associated with obstructive disorders. However, as our lung function measurements consisted of $\mathrm{FEV}_{1}$ and FVC, the type of lung function impairment cannot be definitely identified. One potential mechanism for the present findings suggesting lower lung volumes in a nonfarming population may be obstruction in small airways caused by patchy collapse in early exhalation. In such a case, $\mathrm{FEV}_{1}$ and FVC are decreased and $\mathrm{FEV}_{1} / \mathrm{FVC}$ is normal. ${ }^{23}$ However, the possible contribution of airway obstruction on the suspected restrictive-type impairment would require a bronchodilator test. Confirmation of a true restrictive abnormality would require total lung capacity measurement either with a body plethysmograph or using gas dilution methods. ${ }^{24}$

We have previously shown, in this cohort, that an early farming environment is associated with reduced risk of atopic sensitisation, asthma and atopic diseases at the age of 31 years. ${ }^{2}$ These associations are, therefore, potential explanations for the present observations. However, in additional analyses, when we further adjusted for atopy and doctor-diagnosed asthma, the size of the estimates for the association between early childhood farming environment and current lung function were reduced by $50 \%$ at the most. This suggests that although atopy and asthma probably mediate the effects on improved lung function, other pathways are also likely to be operational. These results imply that an early farming environment may improve lung function, however, not simply by preventing development of atopy and asthma.

Differences in physical activity could also explain the observed differences in lung function. Physical activity is shown to be associated with higher lung function, measured with $\mathrm{FEV}_{1}$ in adulthood, in men and women of all ages. ${ }^{25}$ In the present study, analyses were adjusted for current, but not for childhood, physical activity. It is possible that children living on farms have a higher level of physical activity, as they may participate in physically demanding tasks on farms, as compared with their peers living in non-farming environments. Unfortunately, there is lack of information about levels of physical activity during childhood and, therefore, the effect of childhood physical activity on lung function at the age of 31 years cannot be estimated.

As the differences in the participant's current ${ }^{26}$ or birth weight, as previously shown in this same setting, ${ }^{27}$ 
Table 3 Associations between farming environment during infancy and lung function at the age of 31 years, stratified by gender

\begin{tabular}{|c|c|c|c|c|c|c|}
\hline \multirow[b]{2}{*}{$\begin{array}{l}\text { Farm-related } \\
\text { factors during infancy }\end{array}$} & \multicolumn{3}{|c|}{ Women } & \multicolumn{3}{|l|}{ Men } \\
\hline & $\mathbf{N}$ & $\begin{array}{l}\text { FEV }_{1} \\
\text { difference }(\mathrm{mL}) \\
\text { Adj }(95 \% \mathrm{Cl})\end{array}$ & $\begin{array}{l}\text { FVC } \\
\text { difference }(\mathrm{mL}) \\
\text { Adj }(95 \% \mathrm{Cl})\end{array}$ & $\mathbf{N}$ & $\begin{array}{l}\text { FEV }_{1} \\
\text { difference }(\mathrm{mL}) \\
\text { Adj }(95 \% \mathrm{Cl})\end{array}$ & $\begin{array}{l}\text { FVC } \\
\text { difference }(\mathrm{mL}) \\
\text { Adj }(95 \% \mathrm{Cl})\end{array}$ \\
\hline \multicolumn{7}{|c|}{ Parental professional farming } \\
\hline No & 2178 & 0 & 0 & 2189 & 0 & 0 \\
\hline Yes & 672 & 38 (2 to 75$)$ & $37(-4$ to 78$)$ & 627 & $31(-19$ to 82$)$ & $44(-12$ to 100$)$ \\
\hline \multicolumn{7}{|l|}{ Family had farm animals } \\
\hline No & 1970 & 0 & 0 & 1960 & 0 & 0 \\
\hline Yes & 858 & 49 (15 to 83$)$ & $26(-12$ to 65$)$ & 834 & $11(-36$ to 58$)$ & $-6(-58$ to 47$)$ \\
\hline \multicolumn{7}{|l|}{ Family had dogs ${ }^{*}$} \\
\hline No & 1248 & 0 & 0 & 1230 & 0 & 0 \\
\hline Yes & 1513 & 41 (10 to 71$)$ & 48 (12 to 83 ) & 1482 & $29(-12$ to 70$)$ & $24(-23$ to 71$)$ \\
\hline \multicolumn{7}{|l|}{ Family had cats* } \\
\hline No & 1340 & 0 & 0 & 1427 & 0 & 0 \\
\hline Yes & 1403 & 32 (2 to 63 ) & 40 (5 to 75$)$ & 1237 & 0 (-42 to 42$)$ & $-10(-57$ to 38$)$ \\
\hline \multicolumn{7}{|c|}{ Number of animal species $†$} \\
\hline 0 & 730 & 0 & 0 & 746 & 0 & 0 \\
\hline 1 & 770 & 42 (2 to 82$)$ & 47 (1 to 94$)$ & 769 & $33(-20$ to 87$)$ & $29(-32$ to 91$)$ \\
\hline 2 & 535 & 65 (20 to 110$)$ & $63(10$ to 115$)$ & 511 & $41(-21$ to 102$)$ & $-13(-83$ to 58$)$ \\
\hline 3 & 351 & 93 (40 to 146$)$ & $78(18$ to 139$)$ & 312 & $22(-51$ to 96$)$ & $17(-67$ to 101$)$ \\
\hline 4 or more & 265 & 63 (5 to 122$)$ & 73 (7 to 140$)$ & 220 & $34(-49$ to 117$)$ & $22(-73$ to 117$)$ \\
\hline \multicolumn{7}{|l|}{ Number of cows } \\
\hline 0 & 1987 & 0 & 0 & 1983 & 0 & 0 \\
\hline $1-4$ & 441 & 50 (6 to 95$)$ & $16(-33$ to 66$)$ & 437 & 8 (-51 to 67$)$ & $9(-57$ to 75$)$ \\
\hline 5 or more & 397 & 50 (7 to 93$)$ & $37(-14$ to 88$)$ & 370 & $15(-47$ to 77$)$ & $-7(-77$ to 63$)$ \\
\hline
\end{tabular}

would offer a simple explanation for current findings, we adjusted all the models with both current and birth weight. We also ran the models adjusting for body mass index, instead of weight, at the age of 31 years, but the results were unchanged. Therefore, the associations between a farming environment during infancy and lung function in adulthood are unlikely to be explained by obesity.

Overall, there may be gender differences in respiratory responses to different environmental exposures. In a recent meta-analysis, a higher risk of asthma was observed among women exposed to organic and inorganic dusts as compared with men. By contrast, exposure to organic dust was associated with lower lung function in men compared with women. ${ }^{28}$ In the present study, the associations were mainly observed among women, but this difference between genders did not quite reach nominal statistical significance. These gender differences may be due to differences in biology or in exposure patterns. ${ }^{29}$ In Finland, women and girls have traditionally

Table 4 To explore if the statistically significant associations in table 2 are mediated via the protective effect of childhood farming on atopy and asthma, the models were further adjusted for atopy and asthma

\begin{tabular}{|c|c|c|c|c|c|c|}
\hline \multirow[b]{2}{*}{ Farm-related factors during infancy } & \multicolumn{3}{|c|}{$\mathrm{FEV}_{1}$ difference $(\mathrm{mL})$} & \multicolumn{3}{|c|}{ FVC difference $(\mathrm{mL})$} \\
\hline & Adj & $A d j+A^{*}$ & $A d j+A^{*}+D D A$ & Adj & $A d j+A^{*}$ & Adj+A*+DDA \\
\hline Parental professional farming & 36 & 27 & 22 & 40 & 36 & 31 \\
\hline Family had farm animals & 32 & 23 & 16 & 11 & 6 & -1 \\
\hline Family had dogst & 36 & 33 & 30 & 37 & 36 & 33 \\
\hline
\end{tabular}

Adj: multivariate model, for more detailed information see Methods section.

A: also adjusted for atopy at the age of 31 years.

DDA: also adjusted for doctor-diagnosed asthma ever at the age of 31 years.

*Participants with a weal reaction $\geq 3 \mathrm{~mm}$ to one or more of the four allergens tested were considered to be atopic.

†Before the age of 7 years.

$\mathrm{FEV}_{1}$, forced expiratory volume in $1 \mathrm{~s}$; FVC, forced vital capacity. 
taken care of cattle and other animals, which may partly explain these findings, and also underscores the importance of animal contact during childhood.

As the present study was prospective by nature, we were able to analyse associations between farming environment during infancy and lung function at the age of 31 years without possible recall bias. Because the present study lacked detailed information on farm environment after infancy, it was not possibly to conduct detailed assessments of the effect of farm environment at different time points. However, in the analysis, we have been able to take work-based and home-based exposure to cold, dust, solvents and tobacco smoke at the age of 31 years into account, as well as current farming occupation. Selection among participants not participating in the 31-year follow-up might also misrepresent the observed associations, since almost $50 \%$ of participants attended follow-up, and no drop-out analyses were performed. Furthermore, even in our prospective cohort study, possible healthy worker effect is always a concern. There was no suggestion of healthy worker effect in adulthood as there was no change in the observed associations after adjustment for current farming occupation at the age of 31 years. However, it is possible that some parents of the present study subjects have avoided working in a farm environment due to respiratory problems, which could lead to differences in the genetic predisposition between those living and those not living on a farm in infancy. However, this was less likely in northern Finland in 1966 than it is today. In addition, in the statistical analyses, parental history of allergies and asthma was adjusted for. Therefore, we consider healthy worker effect an unlikely explanation for the present findings.

\section{CONCLUSIONS}

In conclusion, exposure to farming environment during infancy was associated with higher $\mathrm{FVC}$ and $\mathrm{FEV}_{1}$, but not $\mathrm{FEV}_{1} / \mathrm{FVC}$, at the age of 31 years. This suggests that farming environment in early life may have a positive impact on lung function in adulthood, but this needs to be confirmed in future studies.

\footnotetext{
Author affiliations

${ }^{1}$ Department of Health Protection, National Institute for Health and Welfare, Kuopio, Finland

${ }^{2}$ Public Health and Clinical Nutrition, University of Eastern Finland, Kuopio, Finland

${ }^{3}$ Center for Medicine and Clinical Research, Division of Pulmonary Medicine, Kuopio University Hospital, Kuopio, Finland

${ }^{4}$ Department of Obstetrics and Gynecology and MRC Oulu, Oulu University Hospital and University of Oulu, Oulu, Finland

${ }^{5}$ Respiratory Epidemiology and Public Health, Imperial College London, London, UK

${ }^{6}$ Department of Epidemiology and Biostatistics, MRC Health Protection Agency (HPA) Centre for Environment and Health, School of Public Health, Imperial College London, London, UK

${ }^{7}$ Department of Medical and Molecular Genetics, King's College London, London, UK

${ }^{8}$ Institute of Health Sciences, University of Oulu, Oulu, Finland
}

${ }^{9}$ Biocenter Oulu, University of Oulu, Oulu, Finland

${ }^{10}$ Unit of Primary Care, Oulu University Hospital, Oulu, Finland

${ }^{11}$ Department of Children and Young People and Families, National Institute for Health and Welfare, Oulu, Finland

Acknowledgements The authors thank Professor Paula Rantakallio (launch of NFBC1966 and initial data collection) and Mr Markku Koiranen (data management).

Contributors $\mathrm{JL}$ wrote the manuscript and is the guarantor. He also performed the statistical analysis and made substantial contributions to the data interpretation and to the planning of the manuscript. HK made substantial contributions to the writing and planning of the manuscript, statistical analysis and data interpretation. A-LH, AR, ACA and M-RJ made substantial contributions to the writing of the manuscript and data interpretation. JP made substantial contributions to the writing and planning of the manuscript, statistical analysis and data interpretation. All the authors have critically revised and approved the final version of the manuscript.

Funding Financial support was received from the Academy of Finland, Ministry of Health and Social Affair, the University of Oulu; from the University Hospital of Oulu; and from EU H2020-PHC-2014 (grant number 633595): DynaHEALTH - Understanding the dynamic determinants of glucose homeostasis and social capability to promote Healthy and active aging. AR was supported through the European Commission (through project GABRIEL-contract \#018996 under the Integrated Program LSH-2004-1.2.5-1) and the Department of Health, UK. ACA acknowledges the European Commission, Framework 7 (grant number 223367).

\section{Competing interests None declared}

Ethics approval The University of Oulu Ethics Committee approved the study.

Provenance and peer review Not commissioned; externally peer reviewed.

Data sharing statement No additional data are available.

Open Access This is an Open Access article distributed in accordance with the Creative Commons Attribution Non Commercial (CC BY-NC 4.0) license, which permits others to distribute, remix, adapt, build upon this work noncommercially, and license their derivative works on different terms, provided the original work is properly cited and the use is non-commercial. See: http:// creativecommons.org/licenses/by-nc/4.0/

\section{REFERENCES}

1. von Mutius E, Vercelli D. Farm living: effects on childhood asthma and allergy. Nat Rev Immunol 2010;10:861-8.

2. Lampi J, Canoy D, Jarvis D, et al. Farming environment and prevalence of atopy at age 31: prospective birth cohort study in Finland. Clin Exp Allergy 2011;41:987-93.

3. Remes ST, livanainen $\mathrm{K}$, Koskela $\mathrm{H}$, et al. Which factors explain the lower prevalence of atopy amongst farmers' children? Clin Exp Allergy 2003;33:427-34.

4. Linaker C, Smedley J. Respiratory illness in agricultural workers. Occup Med (Lond) 2002;52:451-9.

5. Bardana EJ Jr. 10. Occupational asthma. J Allergy Clin Immunol 2008;121(2 Suppl):S408-11; quiz S421.

6. Radon K. The two sides of the "endotoxin coin". Occup Environ Med 2006;63:73-8, 10.

7. Heller RF, Hayward DM, Farebrother MT. Lung function of farmers in England and Wales. Thorax 1986;41:117-21.

8. Chatzi L, Prokopakis E, Tzanakis N, et al. Allergic rhinitis, asthma and atopy among grape farmers in a rural population in Crete, Greece. Chest 2005;127:372-8.

9. Senthilselvan A, Dosman JA, Kirychuk SP, et al. Accelerated lung function decline in swine confinement workers. Chest 1997;111:1733-41.

10. Dalphin JC, Maheu MF, Dussaucy A, et al. Six year longitudinal study of respiratory function in dairy farmers in the Doubs province. Eur Respir J 1998;11:1287-93.

11. Eduard W, Pearce N, Douwes J. Chronic bronchitis, COPD, and lung function in farmers: the role of biological agents. Chest 2009;136:716-25.

12. Radon K, Schulze A, Ehrenstein V, et al. Environmental exposure to confined animal feeding operations and respiratory health of neighboring residents. Epidemiology 2007;18:300-8. 
13. Northern Finland Birth Cohort 1966, 31-year follow-up study. http:// www.oulu.fi/nfbc/node/18097 (13 May 2015).

14. Omland O, Sigsgaard T, Hjort C, et al. Lung status in young Danish rurals: the effect of farming exposure on asthma-like symptoms and lung function. Eur Respir J 1999;13:31-7.

15. Gainet $M$, Thaon I, Westeel V, et al. Twelve-year longitudinal study of respiratory status in dairy farmers. Eur Respir J 2007:30:97-103.

16. Merchant JA, Naleway AL, Svendsen ER, et al. Asthma and farm exposures in a cohort of rural lowa children. Environ Health Perspect 2005;113:350-6.

17. Fuchs $\mathrm{O}$, Genuneit $\mathrm{J}$, Latzin $\mathrm{P}$, et al. Farming environments and childhood atopy, wheeze, lung function, and exhaled nitric oxide. J Allergy Clin Immunol 2012;130:382-8.e6.

18. Ernst $P$, Cormier $Y$. Relative scarcity of asthma and atopy among rural adolescents raised on a farm. Am J Respir Crit Care Med 2000;161:1563-6.

19. Schulze A, van Strien RT, Praml G, et al. Characterisation of asthma among adults with and without childhood farm contact. Eur Respir $J$ 2007;29:1169-73.

20. Braun-Fahrlander C, Riedler J, Herz U, et al. Environmental exposure to endotoxin and its relation to asthma in school-age children. N Engl J Med 2002;347:869-77.

21. Roponen M, Hyvärinen A, Hirvonen MR, et al. Change in IFN-gamma-producing capacity in early life and exposure to environmental microbes. $J$ Allergy Clin Immunol 2005;116:1048-52.

22. Mendy A, Gasana J, Vieira ER, et al. Endotoxin exposure and childhood wheeze and asthma: a meta-analysis of observational studies. J Asthma 2011;48:685-93.

23. Pellegrino R, Viegi G, Brusasco V, et al. Interpretative strategies for lung function tests. Eur Respir J 2005;26:948-68.

24. Flesch JD, Dine CJ. Lung volumes: measurement, clinical use, and coding. Chest 2012;142:506-10.

25. Nystad W, Samuelsen SO, Nafstad P, et al. Association between level of physical activity and lung function among Norwegian men and women: the HUNT study. Int $J$ Tuberc Lung Dis 2006;10:1399-405.

26. Koenig SM. Pulmonary complications of obesity. Am J Med Sci 2001;321:249-79.

27. Canoy D, Pekkanen J, Elliott $\mathrm{P}$, et al. Early growth and adult respiratory function in men and women followed from the fetal period to adulthood. Thorax 2007;62:396-402.

28. Dimich-Ward H, Beking K, DyBuncio A, et al. Occupational exposure influences on gender differences in respiratory health. Lung 2012;190:147-54.

29. Clougherty JE. A growing role for gender analysis in air pollution epidemiology. Environ Health Perspect 2010;118: 167-76. 